\title{
SYMPOSIUM
}

\section{General Symposium}

H. KÜNEMUND (Convenor). From user integration to usage: recent findings and evidence from Germany. Gerontechnology 2018;17(Suppl):34s; https://doi.org/10.4017/gt.2018.17.s.034.00 Participants B. KLEIN (GERMANY), H. KÜNEMUND (GERMANY), S. MERKEL (GERMANY), H-W. WAHL (GERMANY). Issue Gerontechnology has been criticised because the development of technologies does not seem to have had the starting point in the scientific analysis of old age and its problems - namely, in gerontology, but instead in the available technology (for example, sensor and actor devices) and its further development. The question often seems to have been what can be done with these new technologies to help older people. For some decades now, user integration, user centered design ${ }^{3}$, co-creativity etc. have become more and more imperative. In many aspects the procedures to design everyday objects and technology for older people have indeed improved dramatically, although the main emphasis still seems to be on aspects of usability and user satisfaction ${ }^{1,2}$. Content The symposium brings together experiences and results from the German research in order to evaluate achievements and outcomes of user integration and discuss strategies to further improve design and development of gerontechnology. Structure Barbara Klein puts emphasis on the importance of deployment in real world settings as opposed to prototype testing in pilot sites and laboratories. She reports on the European project CareV.E.T., where the objective is to develop a certified training programme for care staff. Sebastian Merkel presents results of a systematic literature review on participatory methods in gerontechnology. It is shown that participatory design is widely used in different contexts, but the methods differ in regard to persons involved, how and when users are involved and for which reasons this is done. Harald Künemund further problematizes the concept of the "user" involved. He argues that the strategies to design or sample "users" necessarily have shortcomings and promotes the alternative of problem centered design, e.g. starting from a careful evaluation of a gerontological problem instead of arbitrary samples or personae. Barbara Klein reports on a project which starts from such a problem - bathing - and reports on the development of a robotic shower system which enables elderly or disabled individuals to shower independently at home or in care homes. Hans-Werner Wahl finally comments on these presentations and opens the floor for discussing the future of user integration. Conclusion The manifold strategies to integrate users outlined in this symposium are expected to stimulate advances in the development of methods of user integration, provide more clarity on the different functions and pitfalls, and help to further improve the development of technologies which help to assist older people in their daily living activities and help their informal or professional supporters.

\section{References}

1. Glende S, Nedopil C, Podtschaske B, Stahl M, Friesdorf W. Erfolgreiche AAL-Lösungen durch Nutzerintegration - Ergebnisse der Studie "Nutzerabhängige Innovationsbarrieren im Bereich Altersgerechter Assistenzsysteme“. Berlin: Technische Universität Berlin. 2011

2. Nedopil C, Schaube C, Glende S. Guideline: The art and joy of user integration in AAL projects. White paper for the integration of users in AAL projects, from idea creation to product testing and business model development. Brussels: Ambient Assisted Living Association. 2013

3. Norman DA, Draper SW. User Centered System Design: New Perspectives on Human-computer Interaction. Hillsdale: Erlbaum. 1986

Keywords: user integration, user centered design, technology acceptance

Address: Institute of Gerontology, University of Vechta, Germany;

E: harald.kuenemund@uni-vechta.de 


\section{SYMPOSIUM}

\section{General Symposium}

A. SOFIOS, B. KLEIN, A. BAUMEISTER, N. PAPASTAMATIOU, M. PANZIRONI, M. HROMIN, P. KORFOXYLIOTIS, G. PAILOPOULOS, C. PAPADOPOULLU. Can a sensor-based toolkit enable staff in healthcare for work in digitalized environments? Gerontechnology 2018;17(Suppl):35s; https://doi.org/10.4017/gt.2018.17.s.035.00 Purpose Digitalization of work and life is also an issue for residencies for people with intellectual disabilities. Upcoming sensor-based products allow more autonomy of residents and changing work processes for staff. Key issue is qualification in order to utilize these new possibilities. This is taken up by the European project CareV.E.T. (Erasmus+ Strategic partnership for vocational education and training; 2016-1-ELO1-KA202-023612). Objective is to develop a certified training programme for care staff and "supported living operators" at EQF-level 2 and 3 meeting quality assurance requirements according to ISO-Standard 17024:2012. Method A sensor-based toolkit (Figure 1) developed by SenseWorks is the core component. This CareV.E.T toolkit is a plug and play solution for personal activity monitoring comprising of a set of sensors and wearables that can be easily setup in any living area with Wi-Fi supporting WPA2 encryption. The toolkit combining location information from a smart watch and stationary Bluetooth beacons, data from motion and intrusion sensors offers a solution that can deliver adaptive services with regard to the knowledge of users' lifestyle. The toolkit is easy to install, requiring only to place the sensors in the living environment and to provide the local Wi-Fi Password through a web interface or a smart watch Android app. Upon connected to the internet a rule based monitoring platform, using real time data from sensors, allows carers - even the users themselves - to set custom and personalized rules for their safety and wellbeing. Alerts and notifications are sent when the conditions of these rules are violated. Concomitant curriculum provides advanced skills in assistive technologies, social network development, self-advocacy and therapeutic roleplay combining online and work-based elements. In the training, it allows for a digital means for communication, discussing privacy and data security issues and helps also with assessment, treatment, and monitoring of the beneficiaries. The training and toolkit is tested with staff dealing with people with intellectual disabilities in Italy; at the residency for people with intellectual disabilities at Ergastiri in Greece and in the Master course Barrier-free Systems at Frankfurt UAS in Germany. Results \& Discussion A first trial with staff of the user organisations demonstrated the potential of the toolkit which undergoes currently further refinements. It seems to be particularly helpful for training purposes as it can run as a hands-on project in any classroom. In a further extension, the toolkit aims to support independent living for elders and people with disabilities living alone or unsupervised at home. CareV.E.T toolkit puts emphasis on the importance of deployment in real world settings as opposed to prototype testing in pilot sites and laboratories. It aims to minimize numerous instrumentation, implementation and cost barriers, thus allowing care givers and end users to take advantage of these assistive technological developments.

Keywords: sensor-based toolkit, qualification, care homes Address: SenseWorks, 43 Ad Korai, NeaSmyrni, 17122, Greece; E: info@senseworks.gr

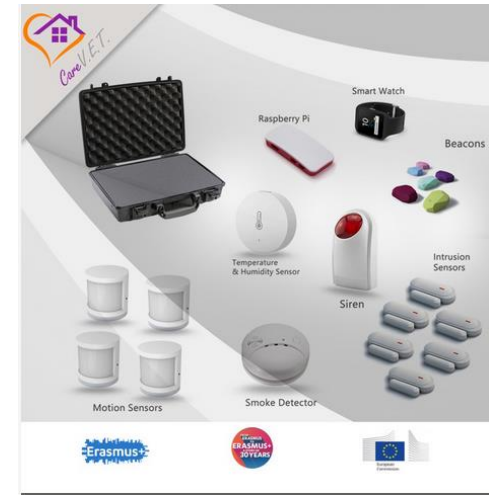

Figure 1. CareV.E.T Toolkit 


\section{SYMPOSIUM}

\section{General Symposium}

S. MERKEL, A. KUCHARSKI. Participatory design and gerontechnology: Findings of a literature review. Gerontechnology 2018;17(Suppl):36s; https://doi.org/10.4017/gt.2018.17.s.036.00 Purpose A central problem that many designers, developers, and manufacturers of products designed for older users are facing is the low uptake of their products ${ }^{1}$. One of the main challenges in this regard is seen in a lack of acceptance by the primary target group, older persons, and the secondary target group, e.g. professional or informal carers ${ }^{2}$. Against this background, the integration of future users into the innovation process has recently gained popularity and participatory design (PD) is seen as a promising way in realising this ${ }^{3,4}$. PD is a design practice that involves non-designers working together with designers and developers and usually involves multiple persons with different backgrounds, experiences, interests, and roles in a joint development/design process. Within the field of gerontology, this leads to the challenge of finding appropriate ways for engaging and involving older persons as well as secondary users in PD activities (ibd.). Despite the recent popularity of PD, critics argue that the involvement of older persons is often not realised properly ${ }^{5}$. To see how PD is implemented and organised in practice, we conducted a literature review. Method The review covered several databases (i.e. Pubmed and Web of Science). Furthermore, we used Google Scholar to include grey literature as well. The search strategy was based on three elements: (1) participatory methods and approaches with, (2) older persons aiming at developing, and (3) technological devices, software and hardware, for older users. To retrieve the relevant data from each article matching the inclusion criteria, a template was developed that guided the extraction process. The template covered different aspects of the studies, including information on the aim of the study, the sample (sample size, age range, etc.), participatory methods used, and the sampling procedure. Results \& Discussion The search strategy revealed 557 publications in total. We reviewed 47 full-text papers, of which 21 were included in the final analysis. We found that PD is widely used in different contexts within the field of gerontechnology. The studies represent a broad variety of technologies designed/developed, ranging from user interfaces to robots, including: (1) The development/design of completely new products, (2) the testing and modification of prototypes, and (3) finding new ways of use for already existing products. Considering the methods and instruments applied, we found that PD was understood and implemented in various ways. This covers the questions who is involved in PD, how and when the future users are involved and for which reasons - why. Although it seems as if PD is continuously popular within the field of gerontechnology, there seems to be a mismatch between the normative presumptions of PD and its practical implementation.

\section{References}

1. Centers for Medicare and Medicaid Services (Greenhalgh T, Shaw S, Wherton J, Hughes G, Lynch J, A'Cour, C, Hinder S, Fahy N, Byrne E, Finlayson A, Sorell T, Procter R. SCALS: A fourth-generation study of assisted living technologies in their organisational, social, political and policy context. BMJ open. 2016 Feb 1;6(2): e010208. https://doi.org/10.1136/bmjopen-2015-010208

2. Lee C, Coughlin JF. PERSPECTIVE: Older Adults' Adoption of Technology: An 971 Integrated Approach to Identifying Determinants and Barriers. J. Prod. Innov. Manag. 2015;32:747-759

3. Compagna D, Kohlbacher $F$. The limits of participatory technology development. The case of service robots in care facilities for older people. In: Technological Forecasting and Social Change. 2015;93:19-31. https://doi.org/10.1016/j.techfore.2014.07.012

4. Bjering H, Curry J, Maeder A. Gerontechnology: The importance of user participation in ICT development for older adults. In: Heather Grain, Fernando J. Martin-Sanchez und Louise K. Schaper (Eds.): Investing in e-health. People, knowledge and technology for a healthy future: selected papers from the $22^{\text {nd }}$ Australian National Health Informatics Conference. 2014

5. Beimborn $M$, Kadi S, Köberer N, Mühleck M, Spindler M. Focusing on the Human: Interdisciplinary Reflections on Ageing and Technology. In: Emma Domínguez-Rué und Linda Nierling (Ed.): Ageing and technology. Perspectives from the social sciences. Bielefeld: Transcript (Science Studies, 9). 2016:311-333

Keywords: participatory design, co-design, literature review

Address: Institute for Work and Technology, Gelsenkirchen, Germany;

E: merkel@iat.eu 


\section{SYMPOSIUM}

\section{General Symposium}

H. KÜNEMUND. Problem centered design: Shifting debates from the user to problems. Gerontechnology 2018;17(Suppl):37s; https://doi.org/10.4017/gt.2018.17.s.037.00 Purpose For a long time, the development of Gerontechnology has been criticized for not taking into account user needs and capabilities. As a consequence, user centered design and related strategies like transdisciplinary development, participatory design, co-creation etc. have become standard procedures. However, some serious problems and open questions remain. Some authors argue, qualitative research and participatory observation are necessary to take into account user needs and preferences ${ }^{1}$ while others prefer personae ${ }^{2}$. In consequence, "users" might be real persons (arbitrarily or self-selected samples), types based on representative, quantitative research (empirical typologies), reconstructions based on qualitative research (theoretical typologies), or simply theoretical imagination (be it experience or prejudice based). In all of these cases, it remains somehow unclear what population these constructed "users" represent and - in consequence - who should later be buying, using, and profiting in which ways from a given Gerontechnology product. The paper tries to argue in favor of an alternative to both user and technology centered strategies in order to widen the scope of methods used in Gerontechnology development. Method In a first step, alternative strategies to include "users" are reviewed and their implications are compared. In the second step, it is argued that these strategies to design or sample "users" necessarily have shortcomings. Empirical base is a representative survey of the population aged 50+ living in private households in Lower Saxony $(n=2,032)^{3}$. Using logistic regressions it is shown that users are not only very complex and diverse, but their needs, interpretations, and preferences change over time (as does the technology and the surrounding world). Results \& Discussion In consequence, it is argued that we should start from an evaluation of a theoretical problem instead of user stories and personas which are based on (mostly) negative images of aging, small and biased samples of potential users, or static representations from survey research. An alternative could be problem centered design, starting from all perspectives: large scale sample surveys, detailed theoretical and empirical knowledge about the phenomenon at hand, and reconstructive methods of problem evaluation at very early stages of technology development. This implies multidisciplinary teams and research prior to the technology development.

\section{References}

1. Birken T, Pelizäus-Hoffmeister H, Schweiger P, Sontheimer L. Technik für ein selbstbestimmtes Leben im Alter - eine Forschungsstrategie zur kontextintegrierenden und praxiszentrierten Bedarfsanalyse. Forum Qualitative Sozialforschung. 2018;19(1):3

2. Compagna D. Partizipation und Moderne: Nutzerorientierte Technikentwicklung als missverstandene Herausforderung. In: Künemund H, Fachinger U (eds.): Alter und Technik. Wiesbaden: Springer. 2018;177-206 3. Künemund $\mathrm{H}$. Wovon hängt die Nutzung technischer Assistenzsystem ab? Expertise zum Siebten Altenbericht der Bundesregierung. Berlin: Deutsches Zentrum für Altersfragen (DZA). 2016

Keywords: user centered design, participatory design, technology acceptance Address: Institute of Gerontology, University of Vechta, Germany;

E: harald.kuenemund@uni-vechta.de 


\section{SYMPOSIUM}

\section{General Symposium}

B. KLEIN, I. SCHLÖMER, H. ROBBERG, A. BAUMEISTER. Robots to assist in activities of daily living?
Approaches for user-centred development. Gerontechnology 2018;17(Suppl):38s; https://doi.org/10.4017/gt.2018.17.s.038.00 Purpose A crucial factor for independent living is being able to carry out activities of daily living (ADL). A recent inventory of robotic development in the healthcare sector ${ }^{1}$ provides $^{-}$ insight in the current state of the art of robotics in the healthcare sector and private homes in Germany ${ }^{1}$. Only few products exist which are intended to overcome functional loss ${ }^{1}$. Katz et al. developed the concept of ADL and a hierarchy within those: Bathing being the most complex, followed by dressing, toileting, transferring, maintaining continence and feeding ${ }^{2}$. What are ways to obtain users opinion on requirements, acceptance factors and ethical issues in order to support a participative development process? Method Frankfurt UAS develops and implements methodological approaches in order to integrate user and stakeholder perspectives already in the development process of robotic systems. Objective is to enhance acceptance and consider ethical issues already in robotic development. Two examples illustrate that: The European project I-SUPPORT (HORIZON 2020 PHC-19-2014/633666) is developing a robotic shower system which enables elderly or disabled individuals to shower independently at home or in care homes (Figure 1). The BMBF project MoblLe (Physical human-robot-interaction for an independent life: 16SV7868) aims to develop interaction modalities for a robotic arm which enables the intake of drinks or food for quadriplegics. First step in these projects is to trace activities and processes around taking a shower, the intake of drinks and food utilizing literature, observation and expert interviews. The analysis of the process takes into account the preparation, the actual performance and subsequent steps, target group(s) and stakeholders as well as assistive aids needed. This information is the basis for an interview guideline for primary and secondary users which is complemented with renderings, video-clips and mock-ups. Thus, interview participants get a first impression what kind of technology they have to expect. Feedback is here on a more advanced knowledge base. Results slip into the design process. In the next round, a more advanced mock-up is presented in the Independent Living Center at Frankfurt UAS, a permanent exhibition in form of a model flat displaying accessible design and assistive technologies. This "living lab" for focus groups allows a more "reality"-experience and users can immerse into the actual situation in order to give an even more qualified feedback. In the focus groups discussion is on usability, acceptance and ethical issues ${ }^{3}$. Results \& Discussion The process model in combination with technological renderings and mock-ups is a suitable instrument for obtaining insights in attitudes, relevant factors of the process and acceptance. Issues discussed with robotic support concern the changed humanhuman and human robot interaction modalities, acceptance and ethics. Surprisingly were the findings with respect to care staff as they constituted a differentiated and new picture on various aspects of the care process.

\section{References}

1. Klein B, Graf B, Schlömer IF, Roßberg H, Röhricht K, Baumgarten S. Robotik in der Gesundheitswirtschaft. Heidelberg: medhochzwei Verlag GmbH, 2018

2. Hauer K, Werle J: I-SUPPORT User Definition. In: I-SUPPROT Models of user abilities and behaviour, use cases and system functionalities. D11:7-20. http://www.i-support-project.eu/web/wp-

content/uploads/2017/11/D1.1.pdf

3. Klein B, Schlömer I. A robotic shower system. In: Z Gerontol Geriat. 2017. https://doi.org/10.1007/s00391017-1345-9

Keywords: robots for activities of daily living, hygiene, eating, care

Address: Frankfurt University of Applied Sciences (UAS), Nibelungenstr. 1, 60318 Frankfurt am Main, Germany;

E: bklein@fb4.fra-uas.de

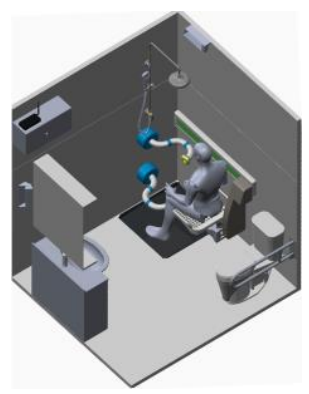

Figure 1. Rendering of the I-SUPPORT robotic shower system: The BioRobotics Institute, Scuola Superiore SantÁnna IT 